Article

\title{
Exploring the Antivirulence Activity of Pulverulentone A, a Phloroglucinol-Derivative from Callistemon citrinus Leaf Extract, against Multi-Drug Resistant Pseudomonas aeruginosa
}

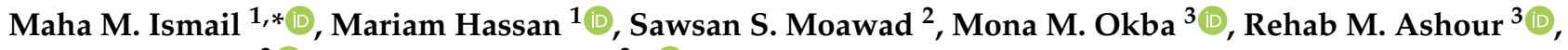 \\ Nesrin M. Fayek ${ }^{3}(D)$ and Fatema R. Saber ${ }^{3, *(D)}$ \\ 1 Microbiology and Immunology Department, Faculty of Pharmacy, Cairo University, Cairo 11562, Egypt; \\ mariam.hassan@pharma.cu.edu.eg \\ 2 Department of Pests and Plant Protection, National Research Center (NRC), Giza 12622, Egypt; \\ ss.moawad@nrc.sci.eg \\ 3 Pharmacognosy Department, Faculty of Pharmacy, Cairo University, Cairo 11562, Egypt; \\ mona.morad@pharma.cu.edu.eg (M.M.O.); rehab.ashour@pharma.cu.edu.eg (R.M.A.); \\ nesrin.fayek@pharma.cu.edu.eg (N.M.F.) \\ * Correspondence: maha.ismail@pharma.cu.edu.eg (M.M.I.); fatema.saber@pharma.cu.edu.eg (F.R.S.); \\ Tel./Fax: +20-3628426 (ext. 00202) (M.M.I.); Tel.: +20-1004405983 (F.R.S.)
}

\section{check for} updates

Citation: Ismail, M.M.; Hassan, M.; Moawad, S.S.; Okba, M.M.; Ashour, R.M.; Fayek, N.M.; Saber, F.R. Exploring the Antivirulence Activity of Pulverulentone A, a PhloroglucinolDerivative from Callistemon citrinus Leaf Extract, against Multi-Drug Resistant Pseudomonas aeruginosa. Antibiotics 2021, 10, 907. https://doi.org/ 10.3390/antibiotics10080907

Academic Editor: Matteo Micucci

Received: 27 June 2021

Accepted: 21 July 2021

Published: 25 July 2021

Publisher's Note: MDPI stays neutral with regard to jurisdictional claims in published maps and institutional affiliations.

Copyright: (c) 2021 by the authors. Licensee MDPI, Basel, Switzerland. This article is an open access article distributed under the terms and conditions of the Creative Commons Attribution (CC BY) license (https:// creativecommons.org/licenses/by/ $4.0 /)$.
Abstract: (1) Background: Bacterial resistance to antibiotics is a global life-threatening issue. Antivirulence therapy is a promising approach to combat bacterial infections as it disarms the bacteria from their virulence factors with reduced selective pressure and a lower chance of resistance. (2) Methods: Callistemon citrinus leaf extract and its major constituent, Pulverulentone A, were tested for their ability to inhibit biofilm, exopolysaccharides, pyocyanin and proteases produced by MDR P. aeruginosa. In addition, a Galleria mellonella larvae model was employed to evaluate the in vivo cytotoxicity of Pulverulentone A and its ability to combat Pseudomonas infection. Docking study was further performed to investigate Pulverulentone A druggability against main quorum sensing (QS) targets expressed by P. aeruginosa; (3) Results: Both C. citrinus extract and the isolated compound could inhibit biofilm formation, extracellular polymeric substances (EPS) and pigment production by the tested isolates. Unexpectedly, no significant inhibition was observed on proteases production. The in silico docking analysis revealed good interactions of Pulverulentone A with all QS targets examined (LasR, MyfR/PqsR, QscR). Pulverulentone A was safe up to $400 \mu \mathrm{g} \cdot \mathrm{mL}^{-1}$ in Galleria caterpillars. Moreover, pre-treatment of $P$. aeruginosa with Pulverulentone A slightly enhanced the survival of the infected larvae. (4) Conclusions: The present study proves Pulverulentone A safety with significant in vitro and in silico antivirulence potential against $P$. aeruginosa.

Keywords: Pseudomonas aeruginosa; Pulverulentone A; myrtaceae; phloroglucinols; virulence; biofilm; pyocyanin; docking; Galleria mellonella

\section{Introduction}

Pseudomonas aeruginosa is considered one of the serious opportunistic bacteria responsible for many life-threatening conditions and hospital-acquired infections globally, including sepsis, urinary tract implant infection and burn and wound infections [1]. It forms biofilms on both biotic and abiotic surfaces which confer resistance to most of the available antibiotics [2]. There were about 32,600 estimated MDR P. aeruginosa infections in hospitalized patients, in addition to 2700 estimated deaths due to this infection, according to what was reported in the USA in 2017 [3]. Carbapenem-resistant $P$. aeruginosa has been listed by $\mathrm{WHO}$ as one of the critical, high-priority pathogens requiring much attention for the discovery and development of novel antimicrobials [4]. Diverse virulence factors of $P$. aeruginosa support its ability to cause diseases and microbial resistance; these include the ability to form biofilm which hinders penetration of antimicrobials, the antioxidant 
pyocyanin pigment which plays an important role in bacterial iron uptake and metabolism, and controls efflux pump genes and monooxygenase genes. Pyocyanin is one of the most important virulence factors as it is capable of inhibiting cell respiration and ciliary movement, leading to the reduction in mucus secretion during airway infections [5].

The need for antivirulence agents and bacterial biofilm inhibitors rather than antimicrobials from natural sources is deemed necessary for applying phytotherapy [6]. Their underlying mechanisms involve quorum sensing (QS) inhibition, disruption of the polymeric biofilm matrix and decrease in the associated virulence factors; these render the bacteria powerless and defenseless with a slighter chance of resistance as a result of the reduced selective pressure exerted on the bacteria [7-9].

There are three well-identified QS systems in P. aeruginosa, Las, Rhl and PQS, and these systems mediate the synthesis of 3-oxo-C12-HSL, C4-HSL and PQS, respectively. Rhl and Pqs are hierarchically mediated by Las. The molecular targets, autoinducers and transcription factors (LasR, QscR, RhlR and MvfR/PqsR) of these QS systems have been well studied $[10,11]$. These QS systems are considered promising drug targets, and they are essential for expression of virulence factors such as pyocyanin and proteases in addition to biofilm formation. Mutations in these systems inhibited pathogenicity of P. aeruginosa [12]. In silico approaches to assess structure-based druggability of a QS system have aided in the development of effective antivirulence agents against bacteria [13].

Previous reports investigated the potential of natural products against several biofilmforming pathogens $[14,15]$. Citrus limonoids, as exemplified by isolimonic acid and hordenine, affected signaling pathways in bacterial cells [16]. Moreover, phenolic compounds, as represented by flavonoids, i.e., quercetin and kaempferol, exhibited a pronounced biofilm inhibition of $S$. mutans and thus were recommended as anti-caries agents.

In the same context, the plant family Myrtaceae exhibits a complex phytochemical make-up with an array of potent bioactivities, where flavonoids, phenolic acids, triterpenes, volatile oils and phloroglucinols together with their corresponding adducts are the most prevalent representatives [17-20]. Myrtenol, a constituent of Myrtus communis essential oil, inhibited the biofilm formation of $S$. aureus at sub-inhibitory concentration, which was further verified by molecular docking [14].

Previous studies have highlighted the antimicrobial activities of essential oils and extracts of Callistemon citrinus [21,22]. In addition, callistemenonone A, a dimeric phloroglucinol isolated from Callistemon viminalis, showed a potent bactericidal action against MRSA [23]. Nevertheless, further studies to explore the antimicrobial and antivirulence potential of bioactive constituents from C. citrinus are still needed for better exploitation of this traditionally used plant.

As a part of our continued research on myrtaceous plants as possible bacterial biofilm inhibitors [6,24], Callistemon citrinus leaves have been investigated for bioactive phytoconstituents. Accordingly, the major phloroglucinol compound, Pulverulentone A, previously isolated from $C$. citrinus extract, has been subjected to detailed microbiological assessment to pinpoint its underlying mechanism against some P. aeruginosa virulence factors and biofilms.

\section{Results and Discussion}

The global spread of microbial resistance makes it urgent to find an alternative way to control infections [25]. Antivirulence therapy involves the attenuation of microbial virulence factors and hence microbial pathogenicity, enhancing the clearance of the infection by the immune system [26].

The aim of this study was to investigate the antivirulence activity of Callistemon citrinus extract and its major isolated constituent, Pulverulentone A, against MDR P. aeruginosa isolates.

The virulence of 10 clinical and environmental isolates of $P$. aeruginosa was screened by assessing the ability of these isolates to form biofilm and to produce pyocyanin pigment. Screening the biofilm formation ability of the isolates revealed that four isolates (PA-1, PA-3, PA-5 and PA-7) showed the ability to form strong biofilm, five isolates (PA-2, PA- 
4, PA-6, PA-9 and PA-10,) were capable of forming weak biofilm and one isolate (PA-8) showed negative biofilm formation. Among the screened isolates, strain PA-7 showed the highest degree of pyocyanin pigmentation, producing $7.21 \pm 0.64 \mu \mathrm{g} \cdot \mathrm{mL}^{-1}$ of pyocyanin while PA-3 and PA-10 strains showed moderate pigmentation, producing $4.26 \pm 1.17$ and $3.03 \pm 1.22 \mu \mathrm{g} \cdot \mathrm{mL}^{-1}$ pyocyanin, respectively. No statistically significant difference exists between the concentration of pyocyanin produced by strain PA-7 and PA-3 (oneway ANOVA, Dunnett's multiple comparisons test, $p=0.0094$ ). Other isolates produced pyocyanin in concentrations ranging from 0.65 to $0.09 \mu \mathrm{g} \cdot \mathrm{mL}^{-1}$ and were regarded as negative pigment producers. The same strains, PA-7 and PA-3, showed the ability to form strong biofilm, with an average BF of 0.47 and 0.62 , respectively, while isolate PA-10 showed weak biofilm formation capability. Consequently, P. aeruginosa isolates PA-7 and PA-3 were chosen for further experiments.

The methylene chloride-methanol extract of $C$. citrinus and the isolated compound Pulverulentone A inhibited the biofilm formation of PA-7 and PA-3 strains in a dose-dependent manner (Figure 1). The tested concentrations of $C$. citrinus extract and Pulverulentone A significantly inhibited biofilm formation (two-way ANOVA, $p<0.005$ and $p<0.0001$, respectively). The $C$. citrinus extract showed $39 \% \pm 8.8 \%$ and $50 \% \pm 6.3 \%$ inhibition of biofilm formed by strains PA-7 and PA-3, respectively, at a concentration of $500 \mu \mathrm{g} \cdot \mathrm{mL}^{-1}$. In addition, Pulverulentone A showed 54\% $\pm 2.6 \%$ and 54\% $\pm 11 \%$ inhibition of biofilm formed by strains PA-7 and PA-3, respectively, at a concentration of $50 \mu \mathrm{g} \cdot \mathrm{mL}^{-1}$. There was no significant difference between the biofilm inhibition activity of $C$. citrinus against the two strains at all the tested concentrations (two-way ANOVA, Sidak's post-test, $p<0.05$ ). The same findings were recorded for the biofilm inhibition activity of Pulverulentone A.

The extracellular polymeric substances (EPS) are considered the major components in the establishment of biofilm systems. Hence, C. citrinus extract and Pulverulentone A were assessed for their ability to inhibit the production of EPS (measured as polysacchairdes) by PA-7 and PA-3 strains (Figure 2). C. citrinus extract and Pulverulentone A both could significantly inhibit EPS production by both strains at the tested concentrations (two-way ANOVA, $p<0.0001)$. The $C$. citrinus extract showed high inhibition percentage of EPS production by strains PA-7 and PA-3, up to $53 \% \pm 6.6 \%$ and $75 \% \pm 0.4 \%$, respectively, at a concentration of $500 \mu \mathrm{g} \cdot \mathrm{mL}^{-1}$ (Figure 2a). The same pattern of EPS production inhibition percentage was observed with Pulverulentone A, with inhibition up to $59 \% \pm 7.4 \%$ and $63 \% \pm 13.3 \%$ for strains PA-7 and PA-3, respectively, at a concentration of $50 \mu \mathrm{g} \cdot \mathrm{mL}^{-1}$ (Figure 2b). There was no significant difference between EPS production inhibition activity of C. citrinus extract/ Pulverulentone A against the two strains at the all tested concentrations except for C. citrinus extract at a concentration of $31.25 \mu \mathrm{g} \cdot \mathrm{mL}^{-1}$ (two-way ANOVA, Sidak's post-test, $p=0.0496)$.

Pyocyanin, a bluish-green redox-active secondary metabolite, plays a crucial role in the virulence of $P$. aeruginosa during infection [27]. It has been reported that the production of pyocyanin by $P$. aeruginosa has adverse effects on the central nervous system, cardiovascular system, respiratory system and urological system [27]. Accordingly, C. citrinus extract and Pulverulentone A were evaluated for their ability to inhibit the production of pyocyanin by PA-7 and PA-3 strains (Figure 3). C. citrinus extract showed inhibition to pyocyanin production up to $83 \% \pm 16.6 \%$ and $69 \% \pm 15.6 \%$ by strains PA-7 and PA-3, respectively, at $500 \mu \mathrm{g} \cdot \mathrm{mL}^{-1}$ (Figure 3a). The same pattern of pyocyanin production inhibition was observed with Pulverulentone A $(72 \% \pm 6.6 \%$ and $55 \% \pm 7.2 \%$ for strains PA-7 and PA-3, respectively) at a concentration of $50 \mu \mathrm{g} \cdot \mathrm{mL}^{-1}$ (Figure $3 \mathrm{~b}$ ). 
Protease enzyme is one of the most important bacterial virulence factors predisposing to cystic fibrosis and wound infections [28]. The results showed that the effect of the C. citrinus extract and Pulverulentone A on the proteolytic activity was isolate-dependent. Unexpectedly, neither the extract nor Pulverulentone A showed any significant inhibitory effect against proteolytic activity of isolate PA-7 (two-way ANOVA, Dunnett's post-test, $p<0.05$ ) (Figure $4 \mathrm{a}, \mathrm{b}$ ); this was unlike what was observed against biofilm, EPS and pigment production. Interestingly, the treatment of isolate PA-3 with C. citrinus extract (at all the tested concentrations) showed significantly higher proteolytic activity when compared to the untreated control (two-way ANOVA, Dunnett's post-test, $p<0.05$ ) (Figure 4a). This may be attributed to the presence of a mixture of different compounds in the $C$. citrinus extract that could interact and enhance the production of proteases by isolate PA-3. The only proteolytic inhibitory activity was observed when isolate PA-3 was treated with Pulverulentone A at concentrations of 12.5 and $25 \mu \mathrm{g} \cdot \mathrm{mL}^{-1}$ (two-way ANOVA, Dunnett's post-test, $p<0.008$ ) (Figure $4 b$ ).

(a)

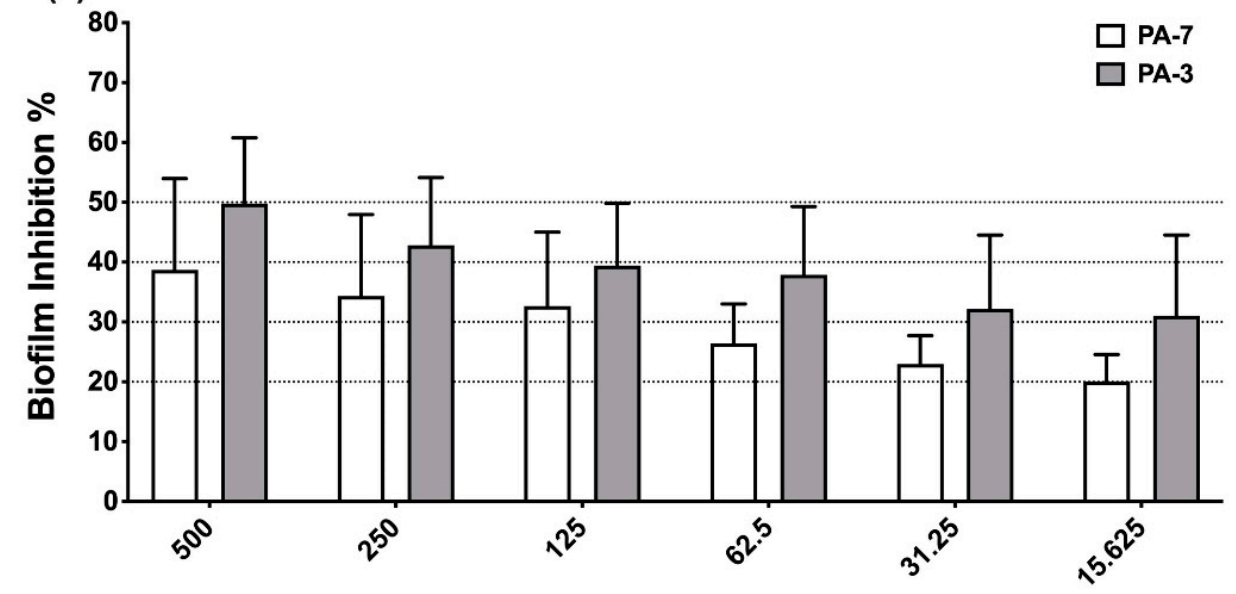

Concentration of Callistemon citrinus extract $\left(\mu \mathrm{g} \cdot \mathrm{mL}^{-1}\right)$

(b)

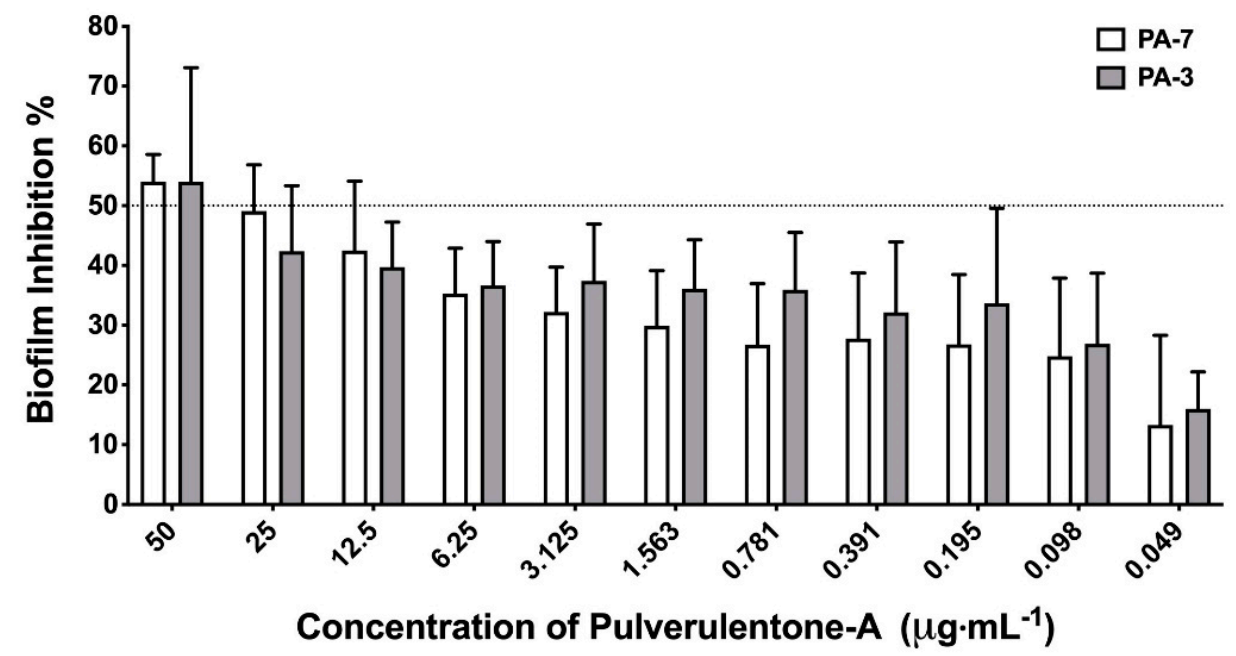

Figure 1. (a) Biofilm inhibition activity of Callistemon citrinus extract against P. aeruginosa PA-7 and PA-3 at concentrations ranging 500-15.625 $\mu \mathrm{g} \cdot \mathrm{mL}^{-1}$. (b) Biofilm inhibition activity of Pulverulentone A against $P$. aeruginosa PA-7 and PA-3 at concentrations ranging $50-0.049 \mu \mathrm{g} \cdot \mathrm{mL}^{-1}$. Data represent the means of biofilm inhibition percentages $\pm \mathrm{SD}, n=3$. A statistically significant difference exists between the effect of the tested concentrations of extract/Pulverulentone A (two-way ANOVA, $p<0.005)$. 
(a)

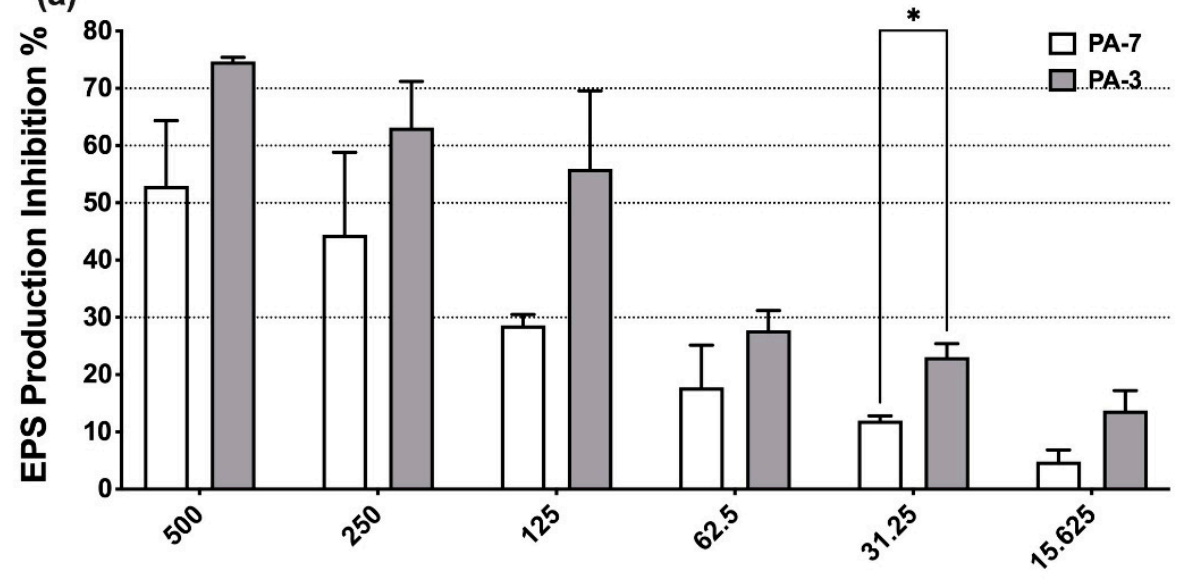

Concentration of Callistemon citrinus extract $\left(\mu \mathrm{g} \cdot \mathrm{mL}^{-1}\right)$

(b)

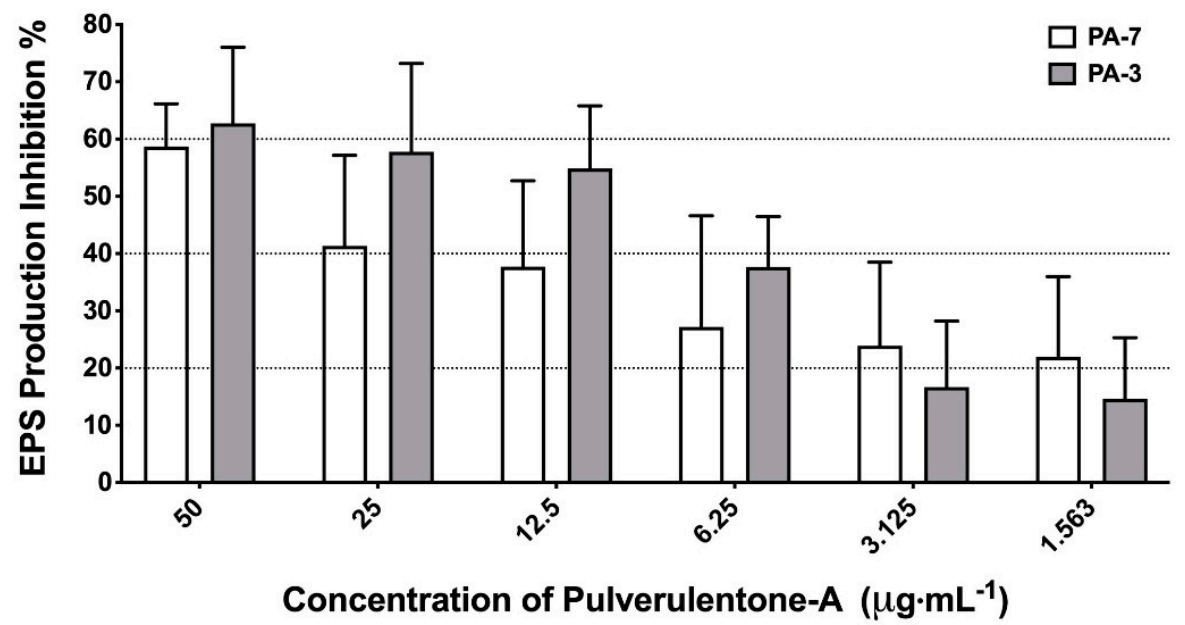

Figure 2. (a) Inhibition percentage of extracellular polymeric substances (EPS) production by Callistemon citrinus extract against $P$. aeruginosa PA-7 and PA-3 at concentrations ranging $500-15.625 \mu \mathrm{g} \cdot \mathrm{mL}^{-1}$. (b) Inhibition percentage of extracellular polymeric substances (EPS) production by Pulverulentone A against P. aeruginosa PA-7 and PA-3 at concentrations ranging $50-1.563 \mu \mathrm{g} \cdot \mathrm{mL}^{-1}$. Data represent the means of EPS production inhibition percentage $\pm \mathrm{SD}, n=3$. A statistically significant difference exists between the effect of the tested concentrations of extract/Pulverulentone A (two-way ANOVA, $p<0.0001$ ). ${ }^{*}$ Means that the difference is significant at $p<0.05$ (two-way ANOVA, Sidak's post-test).

Although the activity of $C$. citrinus extract and Pulverulentone A on biofilm formation (Figure 1) and EPS production (Figure 2) was higher against PA-3 than against PA-7 (with no significant difference, two-way ANOVA, Sidak's post-test, $p<0.05$ ), their inhibitory activities on pyocyanin production (Figure 3 ) were higher against PA-7 than PA-3 strains (non-significant difference, two-way ANOVA, Sidak's post-test, $p<0.05$ ).

The anti-biofilm and anti-pigment production activities observed for both the extract and Pulverulentone A are in agreement with previous findings [24]. Pulverulentone A exhibited higher anti-biofilm activity than the crude C. citrinus extract against MRSA and MSSA biofilms, resulting in $71 \%$ and $62 \%$ inhibition, respectively. Moreover, the same compound displayed the highest degree of staphyloxanthin pigment production inhibition by MRSA and MSSA by an average of $\approx 55 \%$ among the extract and the other isolated compounds, 8-desmethyl eucalyptin and eucalyptin. 
(a)

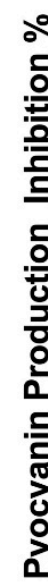

100.

口PA-3

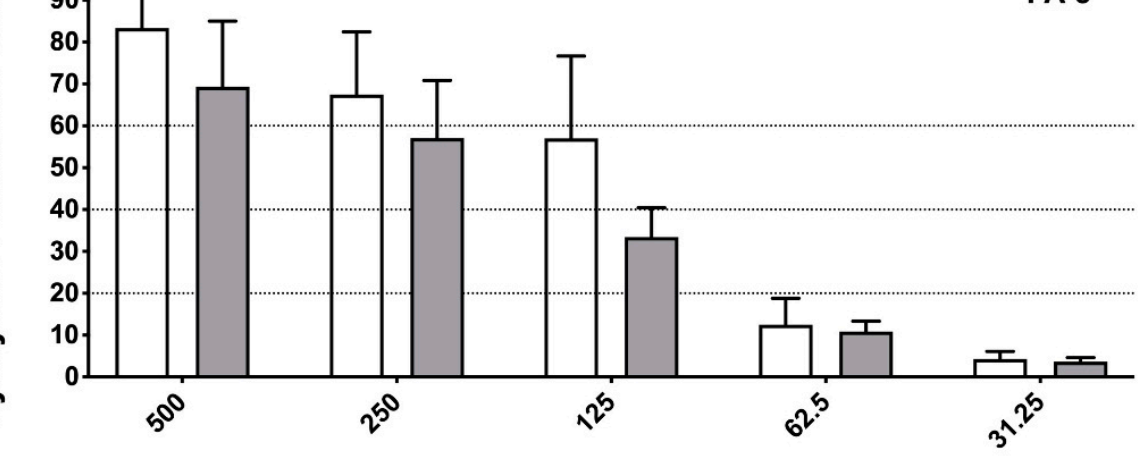

(b) Concentration of Callistemon citrinus extract $\left(\mu \mathrm{g} \cdot \mathrm{mL}^{-1}\right)$

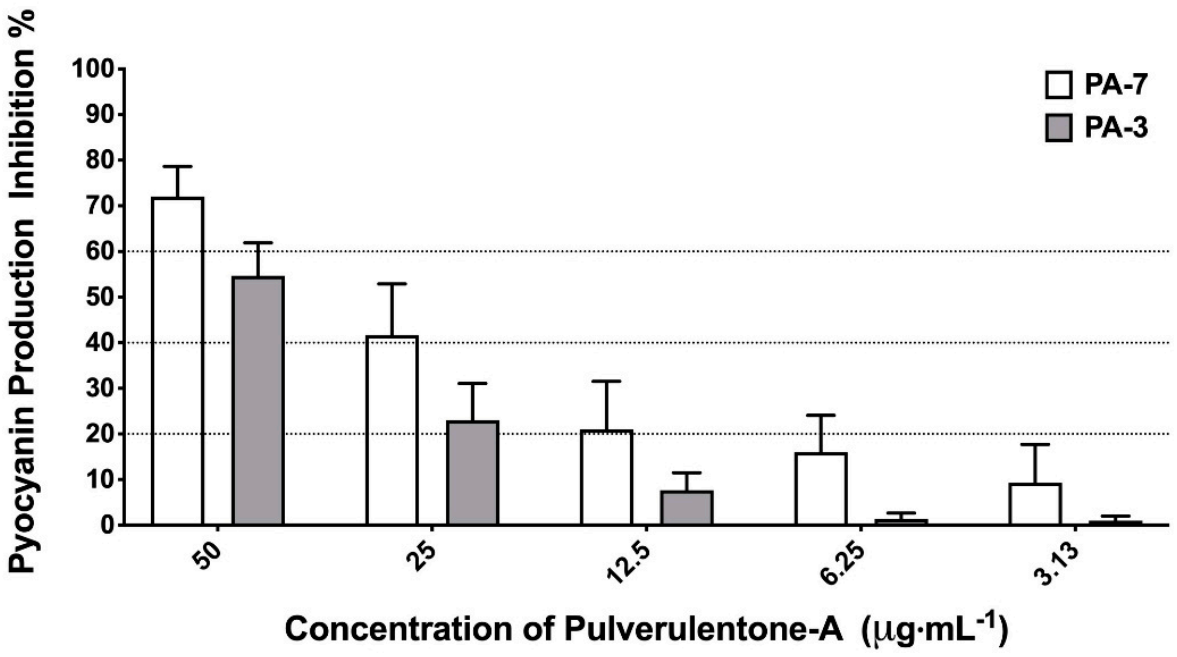

Figure 3. (a) Inhibition percentage of pyocyanin production by Callistemon citrinus extract against P. aeruginosa PA-7 and PA-3 at concentrations ranging $500-125 \mu \mathrm{g} \cdot \mathrm{mL}^{-1}$. (b) Inhibition percentage of pyocyanin production by Pulverulentone-A against PA-7 and PA-3 at concentrations ranging $50-3.125 \mu \mathrm{g} \cdot \mathrm{mL}^{-1}$. Data represent the means of pyocyanin production inhibition percentage $\pm \mathrm{SD}$, $n=3$. A statistically significant difference exists between the effect of the tested concentrations of Pulverulentone A (two-way ANOVA, $p<0.0001$ ).

Several phloroglucinol compounds proved their wide-range inhibition effectiveness against the growth of bacteria and its biofilm formation, such as compounds previously isolated from Hypericum spp [29]. Interestingly, the plant-beneficial microorganisms such as Pseudomonas spp. produce several phloroglucinol derivatives such as 2,4diacetylphloroglucinol, commonly recognized as secondary metabolites with an important role as antibiotics via signaling molecules and as pathogenicity factors [30]. In addition, these phloroglucinol derivatives were recently regarded as effective bio-control agents that provide protection for the plant root system from numerous soil-borne plant diseases [30].

In general, phytochemicals and plant-derived substances are well known for their antimicrobial and antivirulence activities. El-Sayed and co-workers [31] studied the effect of some plant extracts (ethanolic extracts of olive leaf and green tea) on the virulenceassociated traits of the same strains of $P$. aeruginosa employed in this study. They reported $P$. aeruginosa $\mathrm{QS}$ genes to undergo down-regulation upon treatment with olive leaf and green tea extracts. Additionally, strong inhibition of biofilm, twitching motility and pyocyanin production was also observed. Similar activity against $P$. aeruginosa PAO1 was observed 
in another study [32] by hordenine-a major phenolic dietary compound from sprouting parsley extract-at concentrations of 0.5 to $1.0 \mathrm{mg} \cdot \mathrm{mL}^{-1}$. Moreover, hordenine, at the same tested concentrations, could increase the susceptibility of P. aeruginosa PAO1 biofilm to a sub-MIC level of an aminoglycoside antibiotic, netilmicin $\left(0.4 \mu \mathrm{g} \cdot \mathrm{mL}^{-1}\right)$. This combination has led to biofilm formation reduction up to $88 \%$. Hordenine could significantly enhance the effect of netilmicin on P. aeruginosa PAO1 biofilms in a concentration-dependent manner, while sole application of netilmicin showed negligible biofilm reduction.
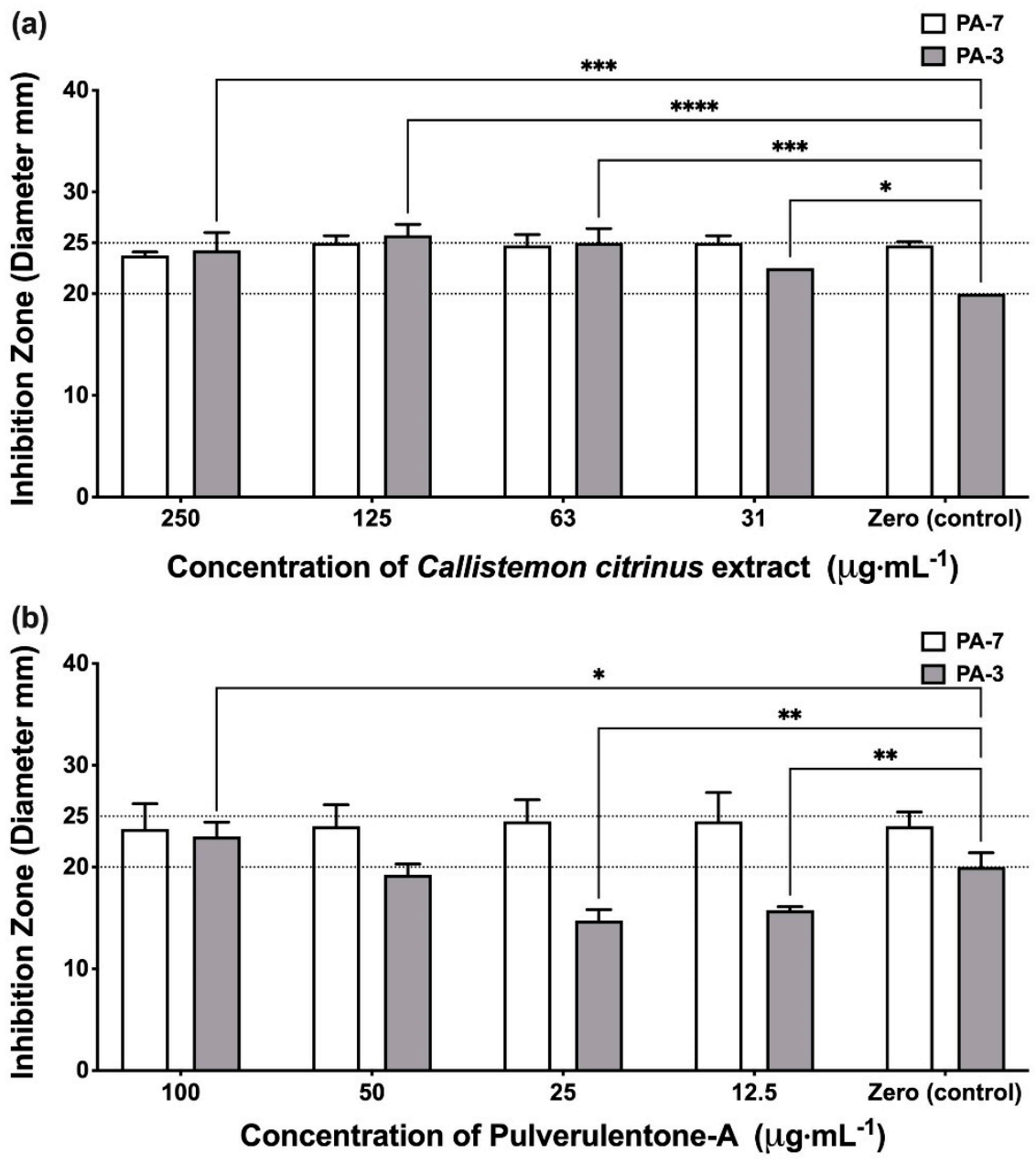

Figure 4. (a) Proteases production inhibition activity of Callistemon citrinus extract against $P$. aeruginosa PA-7 and PA-3 at concentrations ranging $250-31 \mu \mathrm{g} \cdot \mathrm{mL}^{-1}$. (b) Proteases production inhibition activity of Pulverulentone A against P. aeruginosa PA-7 and PA-3 at concentrations ranging $100-12.5 \mu \mathrm{g} \cdot \mathrm{mL}^{-1}$. Data represent the means $\pm \mathrm{SD}, n=3$. A statistically significant difference exists between the effect of the tested concentrations of extract/Pulverulentone A (two-way ANOVA, $p<0.05$ ). ${ }^{*}, * *{ }^{* * *}$ and **** mean that the difference is significant at $p<0.05,0.008,0.0005$ and 0.0001 , respectively (two-way ANOVA, Dunnett's post-test).

Froes and co-workers isolated calycopterin, a major flavonoid from the ethanolic extract of Marcetia latifolia that was tested against P. aeruginosa ATCC 27853 [33], where an inhibitory effect on pyocyanin production by $77.4 \%$ at a concentration of $267.3 \mu \mathrm{M}$ and reduction in the swarming motility in a dose-dependent manner were observed. On the contrary, calycopterin enhanced biofilm formation by the tested strain, which was attributed to the probability of calycopterin to favor the sessile lifestyle of bacteria by increasing c-di-GMP levels, leading to reduction in pyocyanin production and flagellar activity; as a consequence, biofilm formation was enhanced. 
In order to better visualize the possible interactions of Pulverulentone A with the target proteins of Pseudomonas aueroginosa, in silico study has been adopted. Hence, the binding modes and affinities of Pulverulentone A within the binding sites of LasR, MyfR and QscR were examined using molecular docking.

Docking setup was first validated by self-docking of the co-crystalized ligands TY4, CZG and EVY in the vicinity of the binding site of the enzymes LasR, MyfR and QscR, respectively.

TY4 binding with LasR showed a docking score (S) of $-16.8177 \mathrm{kcal} / \mathrm{mol}$ and root mean square deviation (RMSD) $0.7570 \AA$. In addition, TY4 showed strong bond interactions with Leu36, Gly38, Tyr47, Tyr56, Trp60, Arg61, Asp73, Cys79, Leu125 and Ser129 in the enzyme binding sites. Moreover, CZG showed binding with MyfR enzyme with a docking score of $-13.4171 \mathrm{kcal} / \mathrm{mol}$. and RMSD of $0.2396 \AA$ and there was a strong bond interaction with Gln194, Leu207, Arg209, Val211, Trp234, Ile236, Leu254 and Ile263. In addition, the docking score of ligand EVY binding within the active site of QscR was $-16.1479 \mathrm{kcal} / \mathrm{mol}$. and RMSD was $0.6476 \AA$. In addition, EVY had strong bond interactions with Ser38, Gly40, Tyr58, Trp62, Lys63, Asp75, Gly81 and Ile125 (Figures 5-7).

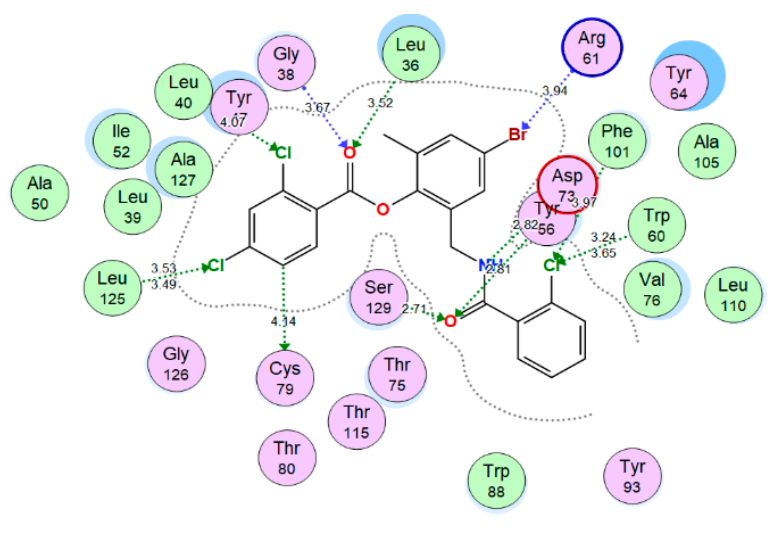

(a)

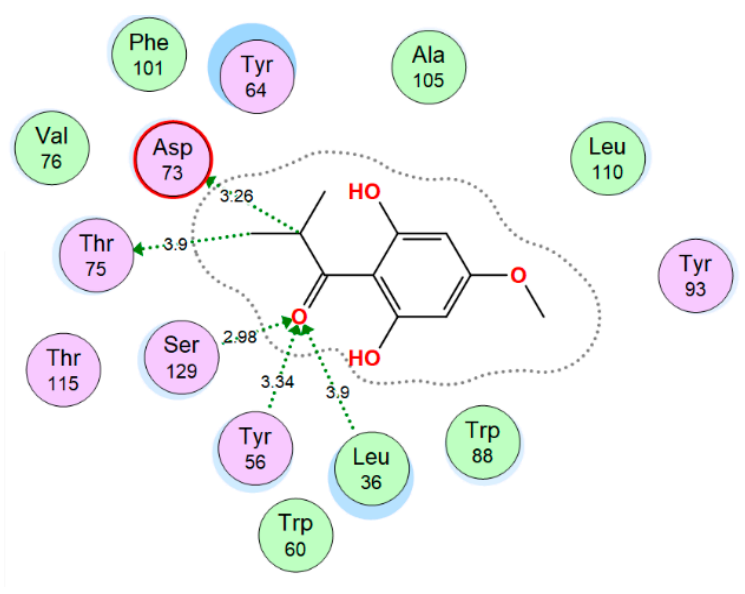

(c)

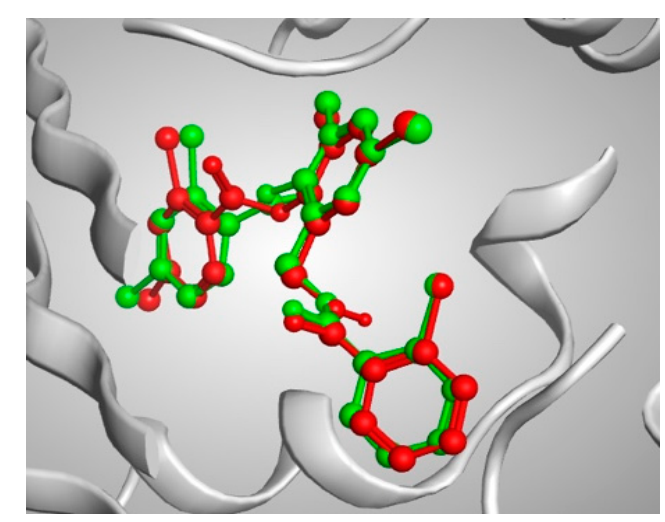

(b)

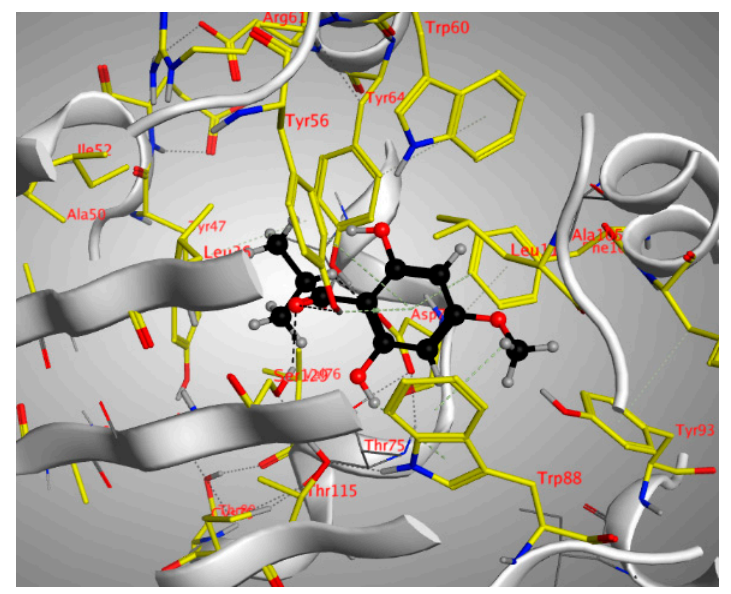

(d)

Figure 5. (a) Two-dimensional interactions of the co-crystallized ligand TY4 within LasR active site, (b) 3D representation of the superimposition of the co-crystallized (red) and the docking pose (green) of CZG in the active site of MvfR/PqsR. (c,d) 2D and 3D diagrams of pulverulentone A interactions within MvfR/PqsR binding site. 


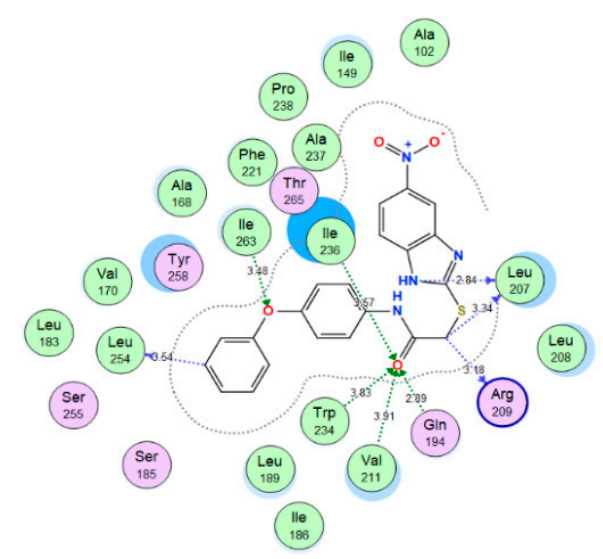

(a)

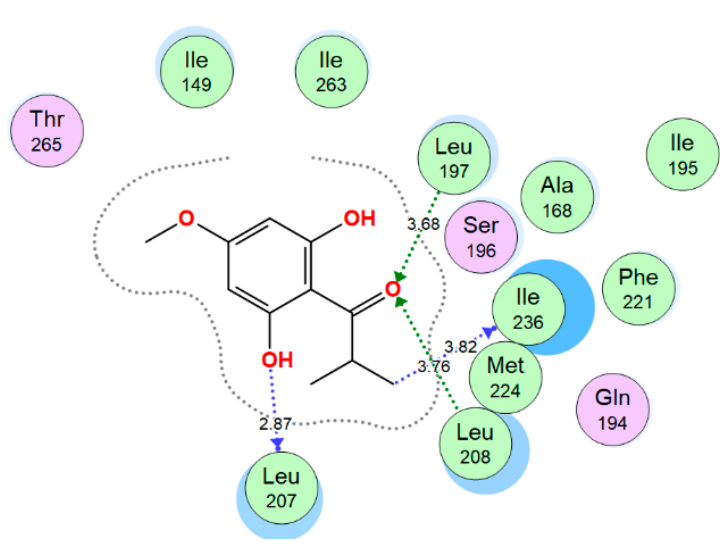

(c)

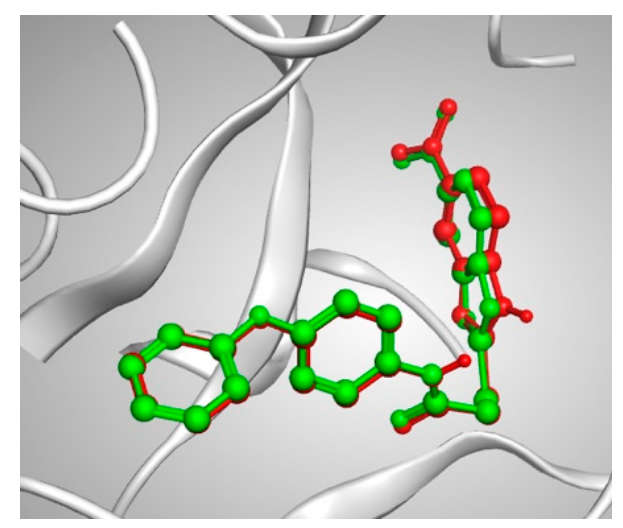

(b)

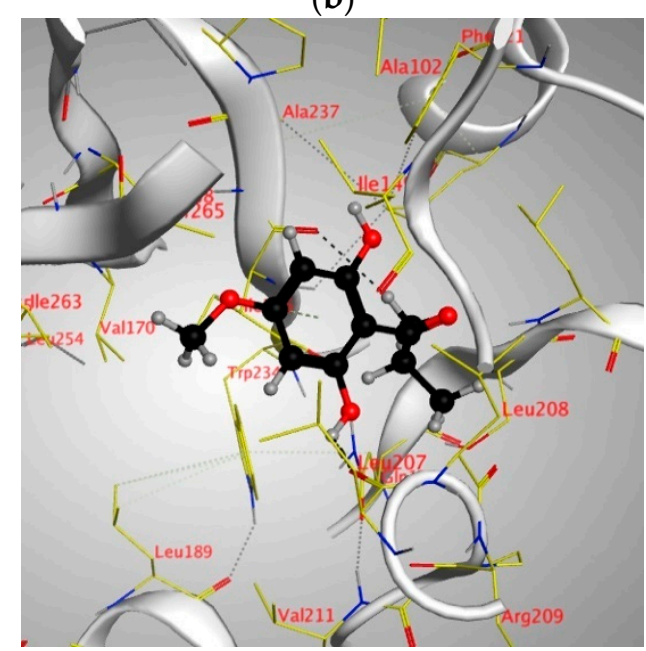

(d)

Figure 6. (a) Two-dimensional interactions of CZG within MvfR/PqsR active site, (b) 3D representation of the superimposition of the co-crystallized (red) and the docking pose (green) of CZG in the active site of MvfR/PqsR, (c,d) 2D and 3D diagrams of Pulverulentone A interactions within MvfR/PqsR binding site.

Pulverulentone A showed good energy binding scores and binding interactions with various amino acids within the active sites of the three examined enzymes (LasR, MyfR and QscR) by both hydrogen bonding and hydrophobic interaction (Table 1). It was noticed that $\mathrm{O}(\mathrm{C}=\mathrm{O})$ and $\mathrm{O} \mathrm{CH}_{3}$ groups of Pulverulentone $\mathrm{A}$ are the interacting groups with LasR, MvfR/PqsR and QscR (Table 1). These outcomes come in accordance with previous results that revealed the pronounced antibacterial effect in parallel with the presence of Pulverulentone A O-methylation and highlighted how much this activity is directly correlated with the acyl side $[34,35]$. The scores and interactions were inferior to that of the co-crystalized ligands, and this can be attributed to the small size of Pulverulentone A relative to the size of the co-crystallized ligands (Figures 5-7); however, it can still interfere with the binding of the natural autoinducers to its receptor, leading to a considerable inhibition of quorum sensing and virulence, as was confirmed by the in vitro biofilm formation, EPS production and pyocyanin inhibition. To the best of our knowledge, this is the first study to examine the druggability of Pulverulentone A against P. aeruginosa QS system enzymes. 


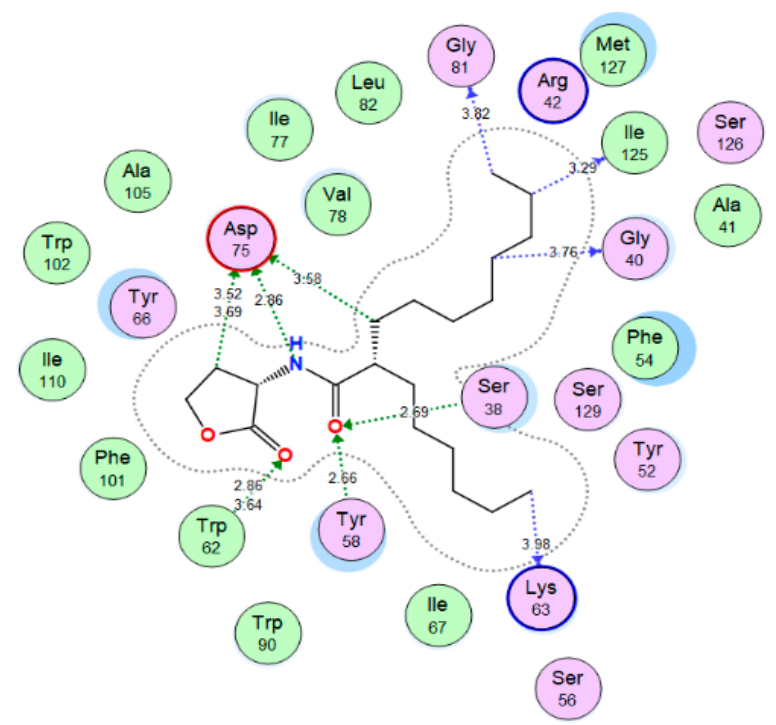

(a)

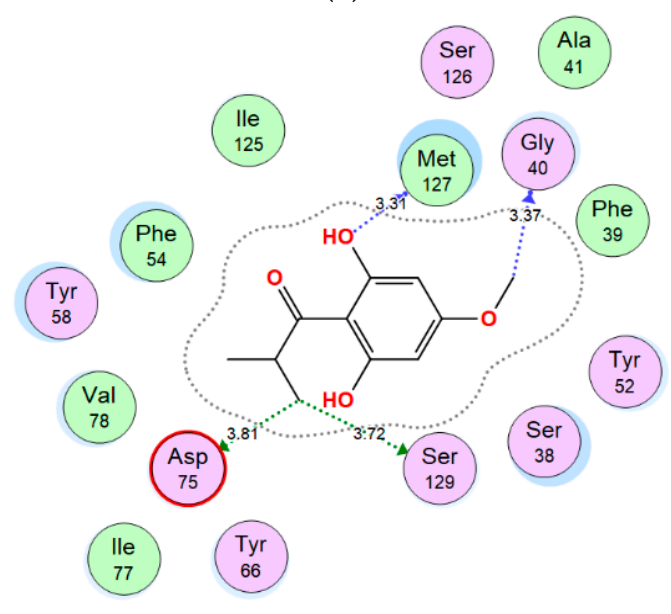

(c)

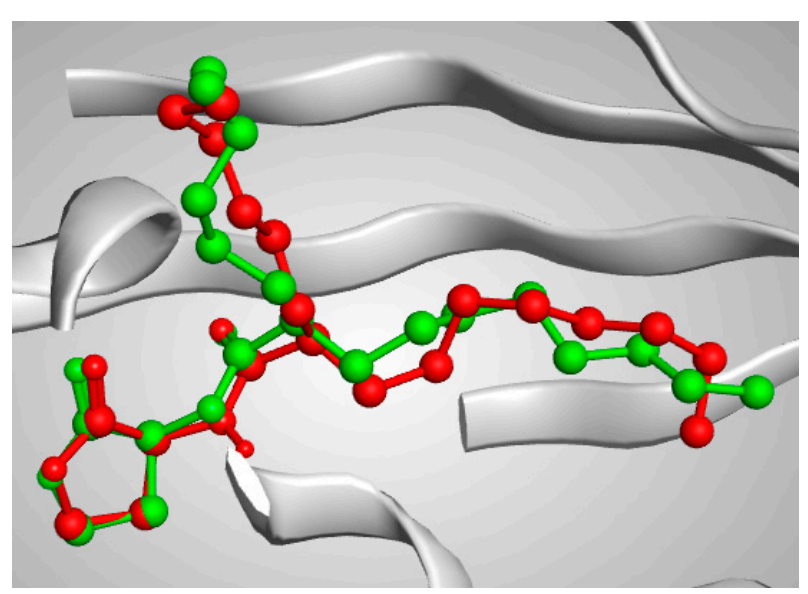

(b)

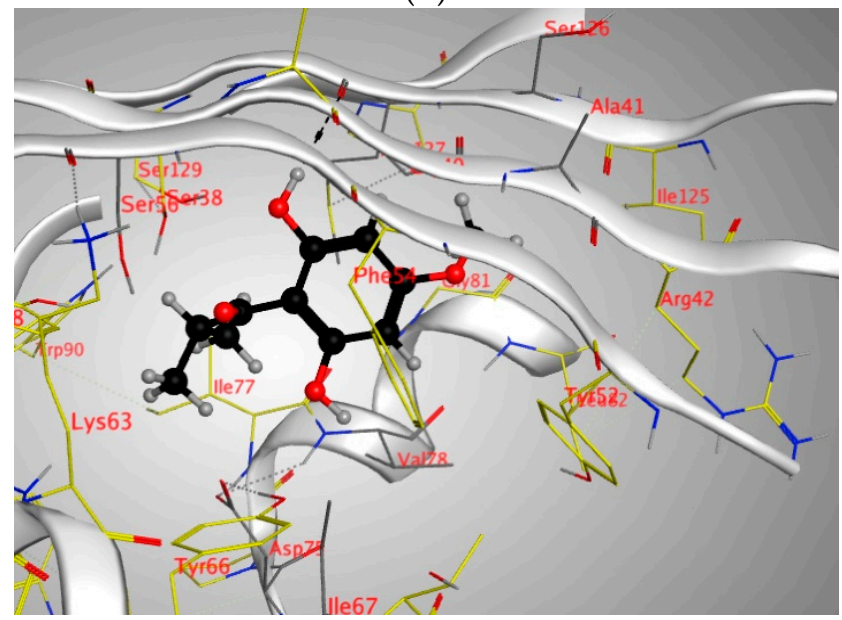

(d)

Figure 7. (a) Two-dimensional interactions of EVY within QscR active site, (b) 3D representation of the superimposition of the co-crystallized (red) and the docking pose (green) of EVY in the active site of QscR, (c,d) 2D and 3D diagrams of Pulverulentone A interactions within QscR binding site.

Table 1. Docking results of binding of Pulverulentone A with LasR, MvfR/PqsR and QscR.

\begin{tabular}{|c|c|c|c|c|c|}
\hline Enzyme & Binding Score (kcal/mol) & Amino Acids & Interacting Groups & Type of Interaction & Bond Length \\
\hline \multirow{5}{*}{ LasR } & \multirow{5}{*}{-12.6517} & Leu36 & $\mathrm{O}(\mathrm{C}=\mathrm{O})$ & H-bond acceptor & 3.90 \\
\hline & & Tyr56 & $\mathrm{O}(\mathrm{C}=\mathrm{O})$ & H-bond acceptor & 3.34 \\
\hline & & Asp73 & $\mathrm{CH}$ & H-bond (non-conventional) & 3.26 \\
\hline & & Thr75 & $\mathrm{CH}_{3}$ & H-bond (non-conventional) & 3.90 \\
\hline & & Ser129 & $\mathrm{O}(\mathrm{C}=\mathrm{O})$ & H-bond acceptor & 2.98 \\
\hline \multirow{4}{*}{ MyfR/PqsR } & \multirow{4}{*}{-9.2847} & Leu197 & $\mathrm{O}(\mathrm{C}=\mathrm{O})$ & H-bond acceptor & 3.68 \\
\hline & & Leu207 & $\mathrm{OH}$ & H-bond donor & 2.87 \\
\hline & & Leu208 & $\mathrm{O}(\mathrm{C}=\mathrm{O})$ & H-bond acceptor & 3.76 \\
\hline & & Ile236 & $\mathrm{CH}_{3}$ & H-bond (non-conventional) & 3.82 \\
\hline \multirow{4}{*}{ QscR } & \multirow{4}{*}{-13.3577} & Gly 40 & $\mathrm{CH}_{3}$ & H-bond (non-conventional) & 3.37 \\
\hline & & Asp75 & $\mathrm{CH}_{3}$ & H-bond (non-conventional) & 3.81 \\
\hline & & Met127 & $\mathrm{OH}$ & H-bond donor & 3.31 \\
\hline & & Ser129 & $\mathrm{CH}_{3}$ & H-bond (non-conventional) & 3.72 \\
\hline
\end{tabular}


Previous studies have examined various compounds of natural and synthetic origin as anti-QS drugs against $P$. aeruginosa and showed results comparable to this study. Zhou et al. [7] investigated the probable binding affinities of the phenolic compound hordenine to the LasR, RhlR and PqsR ligand-binding domains using More2014 module. They observed that the binding affinity of the native autoinducer 3-oxo-C12-HSL with LasR was stronger than the binding of hordenine to LasR active site $(-11.62$ and $-6.72 \mathrm{kcal} / \mathrm{mol}$, respectively). This is in line with this study, where the binding affinity observed by the co-crystalized ligand TY4 with LasR was stronger than that observed for Pulverulentone A to bind LasR. The same compound (hordenine) showed strong binding affinities to both $\mathrm{RhlR}$ and MvfR/PqsR equivalent to that obtained from the interaction of the native ligand to theses enzymes $(-5.5$ and $-6.6 \mathrm{kcal} / \mathrm{mol}$, respectively), which is superior to the binding results of Pulverulentone A to MvfR/PqsR active site obtained in this study.

Furthermore, Abbas et al. [36] reported the antidiabetic drug, sitagliptin, to have antiQS and antivirulence activity against $P$. aeruginosa PAO1 strain at sub-MIC level. It could inhibit production of various virulence factors such as proteases, pyocyanin and hemolysin by $38 \%, 62 \%$ and $92 \%$, respectively. In addition, blocking the swimming, swarming and twitching motilities by $47 \%, 75 \%$ and $77 \%$, respectively, and biofilm inhibition by $54.7 \%$ were recorded. Sitagliptin also interfered with binding of the natural autoinducers with LasR enzyme. Moreover, a reduction in expression of QS genes has been detected, and thus these authors recommended sitagliptin for the treatment of $P$. aeruginosa systemic infections in diabetic patients or topical infections in non-diabetic patients.

The cytotoxicity of Pulverulentone A performed using G. mellonella larvae showed that it was safe at all the tested concentrations up to $400 \mu \mathrm{g} \cdot \mathrm{mL}^{-1}$ (the highest tested concentration). This indicates its suitability for in vivo applications at this concentration range. Caterpillars of the greater wax moth G. mellonella are considered an alternative promising popular model to investigate the efficacy and toxicity of new antimicrobial and antivirulence compounds. Jander et al. [37] reported a significant positive correlation between the virulence of P. aeruginosa in G. mellonella and mice. This indicates the suitability of this insect model to study bacterial pathogenicity and virulence patterns the same as using mice models. Khalil et al. [38] have employed the G. mellonella model to investigate the virulence pattern of carbapenem-resistant strains of K. pneumonia. Another study evaluated the efficacy of a combination of colistin and cotrimoxazole against carbapenemresistant $A$. baumannii, applying the same insect model [39].

Moreover, being an invertebrate, the G. mellonella insect offers a cheaper and simpler model to provide data prior to mammalian studies. In addition, they are affected by the same virulence factors required to infect mammals, and their immune system is identical to mammals, as well [40].

A previous study by Allegra et al. [41] examined and compared the in vivo cytotoxicity testing of low toxicity chemicals using a G. mellonella larvae model and cell culture systems, and it was proven that G. mellonella larvae is a more reliable means for toxicity prediction of low toxicity chemicals than cell culture systems, which overrated their toxicity.

Infection of G. mellonella larvae with PA-7 strain pretreated with either Pulverulentone A at $100 \mu \mathrm{g} \cdot \mathrm{mL}^{-1}$ or sub-MIC of gentamycin $\left(250 \mu \mathrm{g} \cdot \mathrm{mL}^{-1}\right)$ was performed to determine the ability of the isolated compound to enhance the survival of infected larvae. Based on the observed results of the in vitro antivirulence activities of Pulverulentone A, it was hypothesized that it can also prevent a lethal infection in a eukaryotic host. Negative control groups (PBS-injected and quality control group) showed 100\% survival during the experiment.

The survival of the infected caterpillars was slightly enhanced by pretreatment of the bacteria with Pulverulentone A (13\% survival on day 4) compared to pretreatment with sub-MIC of gentamycin (7\% survival on day 4$)$. This difference was found to be non-significant (log-rank (Mantel-Cox) test, $p=0.3034$ ).

The group of larvae infected with non-pretreated P. aeruginosa exhibited $93 \%$ death on day 4 , similar to the group infected with gentamycin-pretreated P. aeruginosa (Figure 8). 
No previous studies on the in vivo antivirulence activity of Pulverulentone A were reported. In a study performed by Tharmalingam et al. [42], a new compound named BIP (4-(1,3-dimethyl-2,3-dihydro-1H-benzimidazol-2-yl)phenol) was identified during high throughput screening for antivirulence compounds against MRSA. These authors reported this compound to prolong the survival of MRSA-infected G. mellonella within $24 \mathrm{~h}$. It is worthy to note that both BIP and Pulverulentone A are phenolic compounds.

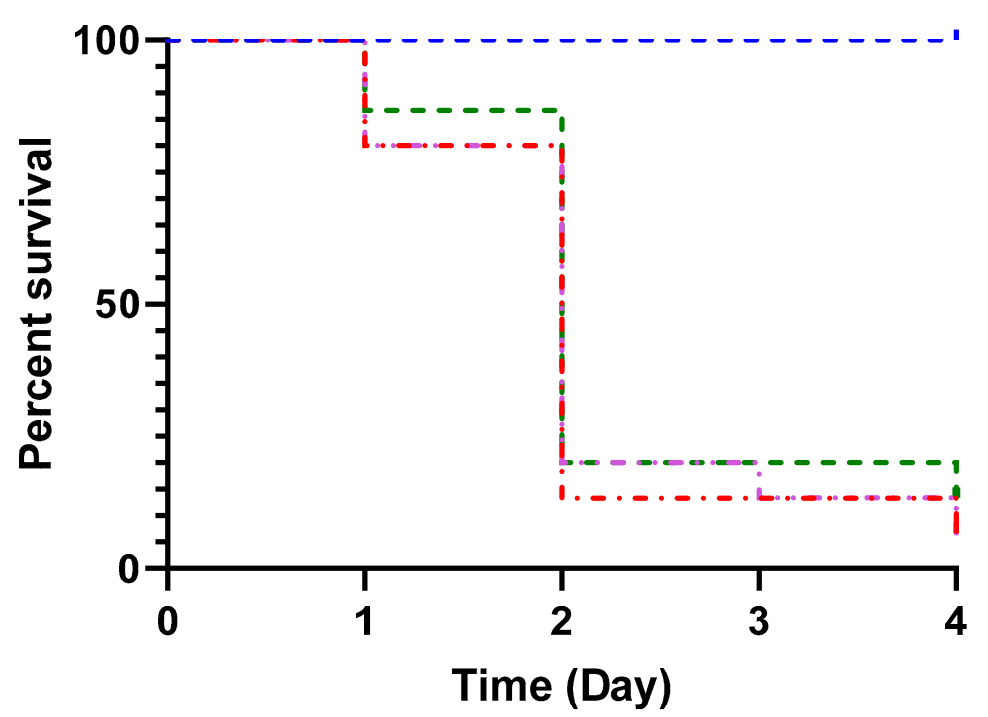

\section{- L. PBS (Vehicle control) \\ - " Infected Non-pretreated \\ - ' $250 \mu \mathrm{g} \cdot \mathrm{m} \mathrm{L}^{-1}$ Gentamycin \\ - L - $100 \mu \mathrm{g} \cdot \mathrm{m} \mathrm{L}^{-1}$ Pulverulentone A}

Figure 8. Percent survival of G. mellonella larvae infected with P. aeruginosae-7 strain within $4 \mathrm{~d}$. PA-7 cells were pretreated with $100 \mu \mathrm{g} \cdot \mathrm{mL}^{-1}$ Pulverulentone A or $250 \mu \mathrm{g} \cdot \mathrm{mL}^{-1}$ gentamycin overnight before infection. Positive control (larvae infected with non-pretreated cells) and negative controls (larvae injected with PBS (vehicle) and larvae non injected (quality control)) were included. Log-rank (Mantel-Cox) test, $p<0.0001, n=15$.

To the best of our knowledge, this is the first study exploring the in vitro, in vivo and in silico potential of Pulverulentone A as a Pseudomonas aeruginosa anti-virulent drug candidate. Our findings recommend further studies on different phloroglucinols and phloroglucinols adducts for the purpose of discovering novel antivirulence hits.

\section{Materials and Methods}

\subsection{Plant Material}

Leaves of Callistemon citrinus Skeels were collected from Orman Botanical Garden, Giza, Egypt. The identity of the plant material was confirmed by Therese Labib, botanical specialist and consultant at Orman and Qubba Botanical Gardens. A voucher specimen (1.07.2019/1) was deposited at Pharmacognosy Department, Faculty of Pharmacy, Cairo University.

\subsection{Preparation of the Extract and Isolation of Pulverulentone $A$}

Details of the preparation of the methylene chloride-methanol extract (80:20) of $C$. citrinus leaves, isolation of Pulverulentone A and NMR data of the compound have been previously described [24]. In brief, the air-dried leaves of Callistemon citrinus were extracted in a Soxhlet apparatus (Glassco, Haryana, India) using methylene chloride:methanol (80:20). All chemicals used are of analytical grade. The crude extract was then applied on a VLC column of Silica Gel H (E-Merck, Darmstadt, Germany) and eluted using gradient system of hexane:ethyl acetate (100:0 to 0:100) followed by $\mathrm{CH}_{2} \mathrm{Cl}_{2} / \mathrm{CH}_{3} \mathrm{OH}$ (100:0 until $20 \%$ methanol). Fractions were monitored by TLC using different solvent systems: hexane-ethyl acetate $(95: 5 v / v)$, hexane-ethyl acetate $(85: 15 v / v)$, methylene chloride-methanol (95:5 $v / v)$ and methylene chloride-methanol $(85: 15 v / v)$. Similar fractions were pooled together. For compounds' visualization on TLC, natural product/polyethylene glycol (NP/PEG) and $p$-anisaldehyde sulphuric acid were used as spray reagents in addition to UV lamp 
(254 \& $365 \mathrm{~nm}$ ) in case of NP/PEG. Consequently, the major fraction II was purified on successive preparative RP-18 TLC Glass plates (E-Merck, Darmstadt, Germany), using $\mathrm{H}_{2} \mathrm{O}: \mathrm{CH}_{3} \mathrm{OH}$ (10:90) as an eluting system. After that, Rp-18 silica column was utilized and eluted with 100\% methanol. Preparative RP-18 HPLC PuriFlash®column (Interchim, Montluçon, France) was finally used, applying gradient elution $\left(\mathrm{H}_{2} \mathrm{O}: \mathrm{CH}_{3} \mathrm{OH}, 20: 80\right.$ to 0:100) for the isolation of Pulverulentone A, which was isolated as $130 \mathrm{mg}$ of white needles.

For structure elucidation of Pulverulentone $\mathrm{A}$, both ${ }^{1} \mathrm{H}$ and ${ }^{13} \mathrm{C}-\mathrm{NMR}$ analyses were recorded on a Bruker AVIIIHD400 FT-NMR spectrometer (400/3) instrument (Kanagawa, Japan). TMS was used as internal standard and chemical shifts were given in $\delta \mathrm{ppm}$ value. Where, the obtained NMR data was in total agreement with the previous report on the methoxylated phloroglucinol compound; Pulverulentone A [43].

\subsection{Microorganisms and Growth Conditions}

Ten clinical and environmental isolates of MDR Pseudomonas aeruginosa were used in this study. The clinical isolates were collected in a previous study from patients in different hospitals in Cairo and Alexandria, Egypt [31]. The isolates were cryopreserved as glycerol stock. The strains were grown aerobically on Luria-Bertani (L.B) agar/broth or Tryptone soy agar/broth (TSA/TSB) (Oxoid, UK) with orbital shaking at $180 \mathrm{rpm}$ at $37^{\circ} \mathrm{C}$ for $24 \mathrm{~h}$. All experiments were conducted in triplicates unless otherwise specified.

\subsection{Effect of the Extract/Pulverulentone A on Biofilm Formation}

3.4.1. Screening for Biofilm Formation by the Tested Isolates

Initially, all P. aeruginosa isolates were screened for their ability to form biofilm. Each isolate was allowed to form biofilm according to the method described by $[25,44]$ with slight modifications. Briefly, overnight culture of each test isolate was prepared in TSB according to the above mentioned growth conditions: the turbidity of each culture was adjusted to $\mathrm{OD}_{600}$ of $0.1-0.125$, then diluted 1:100 in fresh TSB. Then, $120 \mu \mathrm{L}$ of each of the diluted cultures were dispensed in the wells of 96-well flat-bottom microplates. After that, the plates were incubated statically at $37^{\circ} \mathrm{C}$ for $24 \mathrm{~h}$. After incubation, biofilm was stained and visualized as follows: the turbidity of the growth was measured at $\mathrm{OD}_{600}$ before discarding the spent medium and planktonic suspended cells. Wells containing the attached biofilm were washed three times with normal phosphate-buffered saline (PBS) solution, then the plates were left to dry completely. Then, $120 \mu \mathrm{L}$ of $0.1 \%$ crystal violet solution were added to each well and plates were left static for $20 \mathrm{~min}$. The plates were washed three times with de-ionized water and then left to dry completely. Then, $150 \mu \mathrm{L}$ of absolute ethanol were added to each well for $20 \mathrm{~min}$ to extract the violet color of crystal violet. Then, $100 \mu \mathrm{L}$ of the solubilized crystal violet were transferred to a new microplate to be measured at wavelength of $550 \mathrm{~nm}$. The test isolates were classified as strong, moderate, weak or non-biofilm producing according to the following equation [45]:

$$
\mathrm{BF}=\mathrm{AB}-\mathrm{CW}
$$

where $\mathrm{BF}$ is biofilm formation by the test isolate, $\mathrm{AB}$ is $\mathrm{OD}_{550}$ of stained bacteria cells attached to the wells and $\mathrm{CW}$ is $\mathrm{OD}_{550}$ of stained negative control wells (sterile plain medium).

A strong biofilm producing strain results in $\mathrm{BF}>0.300$ and a moderate strain shows $\mathrm{BF}=0.200-0.299$; if $\mathrm{BF}=0.100-0.199$, it is interpreted as a weak biofilm forming strain. A BF value less than 0.100 means the isolate is non-biofilm producing. Only strong or moderate biofilm forming strains were selected to perform further anti-biofilm assays.

\subsubsection{Biofilm Inhibition Activity of the Extract/Pulverulentone A}

C. citrinus leaf methylene chloride-methanol extract and Pulverulentone-A were investigated for their biofilm inhibition activity at the concentrations proven not to cause growth inhibition, discoloration or precipitation when added to the TSB medium (to avoid interference with biofilm visualization). Absence of growth inhibition was assessed by measuring the optical density at $\mathrm{OD}_{600}$ after incubation, while medium discoloration or 
precipitation was assessed by visual examination. The tested concentrations ranged from 500 to $15.625 \mu \mathrm{g} \cdot \mathrm{mL}^{-1}$ and 50 to $0.049 \mu \mathrm{g} \cdot \mathrm{mL}^{-1}$ for the extract and Pulverulentone A, respectively. Biofilm inhibition assay was performed according to abovementioned steps in the presence of either the extract/Pulverulentone A. Both positive control (DMSO, the solvent, was added to the media instead of the C. citrinus extract/Pulverulentone-A) and negative control (uninoculated TSB) were employed.

\subsection{Quantification of Extracellular Polymeric Substances Represented as Polysaccharides}

In order to estimate the extracellular polymeric substances (EPS), which are composed mainly of polysaccharides in addition to nucleic acids and proteins, the procedure described by Nithya et al. [46] was followed. In brief, the relevant isolates were allowed to form biofilm under the same above mentioned conditions in the presence of either the extract or Pulverulentone A at the same mentioned concentrations. After $24 \mathrm{~h}$, planktonic cells and spent medium were discarded and the attached biofilm was washed three times using PBS solution. Then, $50 \mu \mathrm{L}$ of PBS was added to each well, and an equal volume of $5 \%$ phenol $(50 \mu \mathrm{L})$ and 5 volumes $(250 \mu \mathrm{L})$ of concentrated sulfuric acid were added and the mixture was incubated under darkness for $1 \mathrm{~h}$. After incubation, the absorbance of the mixture was measured at $490 \mathrm{~nm}$. Positive control (DMSO, the solvent, was added to the media instead of the $C$. citrinus extract/Pulverulentone-A) was included.

The inhibition \% of EPS production was calculated according to this equation:

$$
\text { EPS Inhibition } \%=\frac{\text { Positive control }_{\mathrm{OD} 490}-\text { Test }_{\mathrm{OD} 490}}{\text { Positive control }_{\mathrm{OD} 490}} \times 100
$$

\subsection{Effect of the Extract/Pulverulentone A on pyocyanin Pigment Production}

Initially, $P$. aeruginosa isolates were screened for their ability to produce pyocyanin pigment in glycerol alanine minimal medium [47]. The optical density of the test strains was adjusted to $\mathrm{OD}_{600}$ of 0.1 , then $200 \mu \mathrm{L}$ of each isolate were dispensed in 96 well Ushaped microplates. Plates were incubated at $37{ }^{\circ} \mathrm{C}$ for $24 \mathrm{~h}$ under orbital shaking at $180 \mathrm{rpm}$. Negative control was included (uninoculated medium). The concentration of pyocyanin pigment produced was determined according to the equation:

$$
\text { Concentration of pyocyanin }\left(\mu \mathrm{g} \cdot \mathrm{mL}^{-1}\right)=\mathrm{OD}_{520} \times 17.072
$$

The ability of the extract/Pulverulentone A to inhibit pyocyanin production was tested under the same growth conditions using the relevant isolates that produced the highest amount of pigment.

Test isolates either treated with the extract/Pulverulentone A (at non-inhibitory concentrations ranging from 500 to $125 \mu \mathrm{g} \cdot \mathrm{mL}^{-1}$ or 50 to $3.125 \mu \mathrm{g} \cdot \mathrm{mL}^{-1}$, respectively) or untreated (positive control using DMSO, the solvent, instead of the C. citrinus extract/PulverulentoneA) were grown in glycerol alanine medium for $24 \mathrm{~h}$ under orbital shaking at $180 \mathrm{rpm}$. Negative control was included. After incubation, pyocyanin was extracted according to the method described by Karatuna and Yagci [47], with some modifications. In brief, the cultures were centrifuged at $6000 \mathrm{rpm}$ for $5 \mathrm{~min}$, the supernatant was separated and an equal volume of chloroform was added with mixing. The aqueous layer was discarded and the chloroform layer (blue color) was acidified with half the volume of $0.2 \mathrm{M} \mathrm{HCl}$. The acidified solution was vortexed and then centrifuged at $6000 \mathrm{rpm}$ for $5 \mathrm{~min}$. The absorbance $\left(\mathrm{OD}_{520}\right)$ of the aqueous acidic layer (pink color) was measured using a microplate reader (BioTek Synergy 2, Winooski, VT, USA). Pyocyanin inhibition \% was calculated using the following equation:

$$
\text { Inhibition } \%=\frac{\text { Positive control }_{\mathrm{OD} 520}-\text { Test }_{\mathrm{OD} 520}}{\text { Positive control }_{\mathrm{OD} 520}} \times 100
$$




\subsection{Effect of the Extract/Pulverulentone A on the Proteases Production}

The ability of the extract/Pulverulentone A to inhibit proteases production was examined according to the method described by Vijayara-ghavan and Vincent [48]. In brief, cultures of relevant $P$. aeruginosa isolates either untreated or treated with extract/Pulverulentone A in LB broth were incubated overnight. The cultures were centrifuged at $15,000 \mathrm{rpm}$ for $20 \mathrm{~min}$. Then, $100 \mu \mathrm{L}$ aliquots of the supernatants were collected and added to the wells made in $5 \%$ skim milk agar plates and incubated overnight at $37^{\circ} \mathrm{C}$. The zones of inhibition were measured and compared to the positive control.

\subsection{Molecular Docking Study}

The binding modes and affinities of Pulverulentone A, within LasR, MvfR (PqsR) and PscR receptors in P. aeruginosa, were predicted using molecular docking. All the molecular modeling studies were carried out using Molecular Operating Environment (MOE, 2019.0102) software. All minimizations were performed with MOE until a root mean square deviation (RMSD) gradient of $0.1 \mathrm{kcal} \cdot \mathrm{mol}^{-1} \AA^{-1}$ with MMFF94x force field and the partial charges were automatically calculated. The $X$-ray crystallographic structure of LasR co-crystalized with 4-bromo-2-(\{[(2-chlorophenyl)carbonyl]amino\}methyl)6-methylphenyl 2,4-dichlorobenzoate (TY4) (PDB ID: 3JPU) was downloaded from the protein data bank (https://www.rcsb.org/structure/3JPU). The X-ray crystallographic structure of MyfR co-crystalized with 2-[(5-nitro-1H-benzimidazol-2-yl)sulfanyl]-N-(4phenoxyphenyl)acetamide (CZG) (PDB ID: 6B8A) was downloaded from the protein data bank (https://www.rcsb.org/structure/6B8A). The X-ray crystallographic structure of QscR co-crystalized with (2S)-2-hexyl-N-[(3S)-2-oxooxolan-3-yl]decanamide (EVY) (PDB ID: 6CBQ) was downloaded from the protein data bank (https://www.rcsb.org/ structure /6CBQ). For each co-crystallized enzyme, the protein data bank was accessed on 10 April 2021.

For each co-crystallized enzyme, the water molecules and ligands that are not involved in the binding were removed, and the protein was prepared for the docking study using Protonate 3D protocol in MOE with default options. The co-crystalized ligands (TY4, CZG and EVY) were used to define the binding site for docking. Triangle Matcher placement method and London dG scoring function were used for docking.

\subsection{In Vivo Cytotoxicity of Pulverulentone A Using Galleria mellonella Larvae Model}

The cytotoxicity of Pulverulentone A was evaluated using the larvae of G. mellonella according to the method described by Allegra et al. [41]. Final instar stages of G. mellonella larvae were supplied by Pests and Plant Protection department, National Research Center, Egypt. Caterpillars of average weight of $200 \mathrm{mg}$ were employed in the test. Cytotoxicity of Pulverulentone A was tested at concentrations of 400, 200, 100, 50, 25 and $12.5 \mu \mathrm{g} \cdot \mathrm{mL}^{-1}$ prepared in sterile PBS. After disinfecting the injection site with $70 \%$ alcohol, $10 \mu \mathrm{L}$ of each concentration were injected in the last right proleg of each group of 10 larvae using a 100-unit insulin syringe. Larvae were incubated at room temperature $\left(25 \pm 2{ }^{\circ} \mathrm{C}\right)$ and observed every day for 4 days for any signs of death (blackening/increased melanization with loss of movement). One group of 10 larvae was injected with $10 \mu \mathrm{L}$ of sterile PBS and served as the negative control group and another group was not injected (quality control group). The maximum safe concentration of Pulverulentone A causing no mortality to the larvae was determined among the tested concentrations (400 to $12.5 \mu \mathrm{g} \cdot \mathrm{mL}^{-1}$ ). The experiment was performed twice.

\subsection{Survival of Galleria mellonella Larvae Model Infected with Non-Pretreated or Pretreated P. aeruginosa with Pulverulentone $A$}

In order to investigate the in vivo antivirulence activity of Pulverulentone A, a $G$. mellonella larvae model as described by Peleg et al. [49] with some modifications was employed. Final instar stages of G. mellonella caterpillars at the same status described above were used in this assay. Gentamycin was used as drug control at sub-MIC. (Its MIC 
was previously determined [31] and confirmed in this study to be $1 \mathrm{mg} \cdot \mathrm{mL}^{-1}$. In brief, twofold serial dilutions of gentamycin ranging from 4000 to $30 \mu \mathrm{g} \cdot \mathrm{mL}^{-1}$ were prepared in LB broth. In a 96-well microplate, $100 \mu \mathrm{L}$ of each concentration was added to $100 \mu \mathrm{L}$ of an overnight culture in LB broth of PA-7 isolate adjusted to $10^{6} \mathrm{CFU} \cdot \mathrm{mL}^{-1}$. The plate was incubated at $37^{\circ} \mathrm{C}$ for $24 \mathrm{~h}$. The MIC was determined by recording the lowest concentration that caused complete growth inhibition as was detected by the naked eye and was confirmed by measuring the OD at $600 \mathrm{~nm}$ compared to the positive control [50].) A total of 75 caterpillars were divided into 5 groups. Each included 15 caterpillars and received the respective treatment in form of injection in the last right proleg as follows:

Group I: Received $10 \mu \mathrm{L}$ of $10^{4}$ CFU.mL ${ }^{-1}$ of P. aeruginosa isolate-PA-7 pre-treated with $100 \mu \mathrm{g} \cdot \mathrm{mL}^{-1}$ of Pulverulentone A.

Group II: Received $10 \mu \mathrm{L}$ of $10^{4} \mathrm{CFU} \cdot \mathrm{mL}^{-1}$ of P. aeruginosa isolate-PA-7 pretreated with $250 \mu \mathrm{g} \cdot \mathrm{mL}^{-1}$ of gentamycin; represents $0.25 \times$ MIC.

Group III: Received $10 \mu \mathrm{L}$ of $10^{4} \mathrm{CFU} \cdot \mathrm{mL}^{-1}$ of un-pretreated P. aeruginosa isolate-PA-7 (positive control).

Group IV: Received $10 \mu \mathrm{L}$ of sterile PBS solution (negative vehicle control).

Group V: Did not receive any treatment injection (quality control).

The caterpillars were incubated at room temperature as stated above and observed daily for 4 days for any signs of death. The experiment was performed twice.

\subsection{Statistical Analysis}

Statistical analysis was performed using GraphPad Prism 9.0.2 (GraphPad Software, Inc., San Diego, CA, USA).

\section{Conclusions}

Pulverulentone A could be proven as a potential scaffold for further optimization in the discovery of anti-virulence drugs. It is recommended to be considered as a lead compound in the semi-synthesis of new plant-based anti-virulent drugs. Furthermore, being recently reported as a potent MRSA anti-virulent agent, this study scientifically validates the P. aeruginosa anti-virulent potential of Pulverulentone A along with its in vivo safety. The perspective of our future studies will focus on the effect of this promising drug candidate on the quorum sensing pathways of different clinically isolated Gram-positive and Gram-negative bacteria and other microbial pathogens.

Author Contributions: Conceptualization, M.M.I., M.H., F.R.S. and S.S.M.; methodology, M.M.I., M.H., F.R.S., N.M.F., R.M.A., M.M.O. and S.S.M.; software, M.M.I., M.H. and F.R.S.; validation, M.M.I., M.H. and F.R.S.; formal analysis, M.M.I., M.H., F.R.S. and S.S.M.; investigation, M.M.I., M.H., F.R.S., N.M.F., R.M.A., M.M.O. and S.S.M.; resources, M.M.I., M.H., F.R.S., N.M.F., R.M.A., M.M.O. and S.S.M.; data curation, M.M.I., M.H., F.R.S., N.M.F., R.M.A., M.M.O. and S.S.M.; writing-original draft preparation, M.M.I., M.H., F.R.S., N.M.F., R.M.A., M.M.O. and S.S.M.; writing-review and editing, M.M.I., M.H. and F.R.S.; visualization, M.M.I., M.H. and F.R.S.; supervision, M.M.I. and F.R.S.; project administration, F.R.S. and M.M.I.; funding acquisition, F.R.S. and M.M.I. All authors have read and agreed to the published version of the manuscript.

Funding: This research was funded by Faculty of Pharmacy, Cairo University, Interdisciplinary Research Grant project (IRG 2019-2021), and the APC was equally funded by Faculty of Pharmacy and Cairo University.

Institutional Review Board Statement: Not applicable.

Informed Consent Statement: Not applicable.

Data Availability Statement: Available upon request.

Acknowledgments: The authors would like to acknowledge Reham Samir, Microbiology and Immunology Department, Faculty of Pharmacy, Cairo University, Egypt, and Nazly El-Sayed, Microbiology and Immunology Department, Faculty of Pharmacy, 6th October University, Egypt, as they generously offered the bacterial isolates used in this study. 
Conflicts of Interest: The authors declare no conflict of interest.

\section{References}

1. Kierbel, A.; Gassama-Diagne, A.; Rocha, C.; Radoshevich, L.; Olson, J.; Mostov, K.; Engel, J. Pseudomonas aeruginosa exploits a PIP3-dependent pathway to transform apical into basolateral membrane. J. Cell Biol. 2007, 177, 21-27. [CrossRef] [PubMed]

2. Pericolini, E.; Colombari, B.; Ferretti, G.; Iseppi, R.; Ardizzoni, A.; Girardis, M.; Sala, A.; Peppoloni, S.; Blasi, E. Real-time monitoring of Pseudomonas aeruginosa biofilm formation on endotracheal tubes in vitro. BMC Microbiol. 2018, 18, 1-10. [CrossRef] [PubMed]

3. Centers for Disease Control and Prevention. Centers for Disease Control and Prevention: Antibiotic Resistance Threats in the United States; Centers for Disease Control and Prevention: Atlanta, GA, USA, 2019.

4. World Health Organization. Global Priority List of Antibiotic-Resistant Bacteria to Guide Research, Discovery and Development of New Antibiotics; WHO: Geneva, Switzerland, 2017.

5. Silva, L.N.; Zimmer, K.R.; Macedo, A.J.; Trentin, D. Plant Natural products targeting bacterial virulence factors. Chem. Rev. 2016, 116, 9162-9236. [CrossRef] [PubMed]

6. Ismail, M.M.; Samir, R.; Saber, F.R.; Ahmed, S.R.; Farag, M.A. Pimenta Oil as A Potential Treatment for Acinetobacter Baumannii wound infection: In vitro and in vivo bioassays in relation to its chemical composition. Antibiotics 2020, 9, 679. [CrossRef] [PubMed]

7. Zhou, J.-W.; Muhammad, J.; Sun, B.; Yang, R.; Wadood, A.; Wang, J.-S.; Jia, A.-Q. Metabolomic analysis of quorum sensing inhibitor hordenine on Pseudomonas aeruginosa. Appl. Microbiol. Biotechnol. 2019, 103, 6271-6285. [CrossRef]

8. Zhong, L.; Ravichandran, V.; Zhang, N.; Wang, H.; Bian, X.; Zhang, Y.; Li, A. Attenuation of Pseudomonas aeruginosa Quorum Sensing by Natural Products: Virtual Screening, Evaluation and Biomolecular Interactions. Int. J. Mol. Sci. 2020, 21, 2190. [CrossRef]

9. Ezzat, M.I.; Hassan, M.; Abdelhalim, M.A.; El-Desoky, A.M.; Mohamed, S.O.; Ezzat, S.M. Immunomodulatory effect of Noni fruit and its isolates: Insights into cell-mediated immune response and inhibition of LPS-induced THP-1 macrophage inflammation. Food Funct. 2021, 12, 3170-3179. [CrossRef]

10. Lee, J.; Zhang, L. The hierarchy quorum sensing network in Pseudomonas aeruginosa. Protein Cell 2015, 6, 26-41. [CrossRef]

11. Lee, J.; Wu, J.; Deng, Y.; Wang, J.; Wang, C.; Wang, J.; Chang, C.; Dong, Y.; Williams, P.; Zhang, L.-H. A cell-cell communication signal integrates quorum sensing and stress response. Nat. Chem. Biol. 2013, 9, 339-343. [CrossRef]

12. Bjarnsholt, T.; Jensen, P.Ø.; Jakobsen, T.H.; Phipps, R.; Nielsen, A.K.; Rybtke, M.T.; Tolker-Nielsen, T.; Givskov, M.; Høiby, N.; Ciofu, O. Quorum Sensing and Virulence of Pseudomonas aeruginosa during Lung Infection of Cystic Fibrosis Patients. PLoS ONE 2010, 5, e10115. [CrossRef]

13. Froes, T.; Baldini, R.L.; Vajda, S.; Castilho, M.S. Structure-based Druggability assessment of anti-virulence targets from pseudomonas aeruginosa. Curr. Protein Pept. Sci. 2019, 20, 1189-1203. [CrossRef]

14. Cordeiro, L.; Figueiredo, P.; Souza, H.; Sousa, A.; Andrade-Júnior, F.; Barbosa-Filho, J.; Lima, E. Antibacterial and Antibiofilm Activity of Myrtenol against Staphylococcus aureus. Pharmaceuticals 2020, 13, 133. [CrossRef] [PubMed]

15. Elzeini, H.M.; Ali, A.R.A.A.; Nasr, N.F.; Hassan, M.; Hassan, A.A.M.; Elenany, Y.E. Probiotic capability of novel lactic acid bacteria isolated from worker honey bees gut microbiota. FEMS Microbiol. Lett. 2021, 368, fnab030. [CrossRef] [PubMed]

16. Vikram, A.; Jesudhasan, P.R.; Jayaprakasha, G.; Pillai, S.D.; Patil, B.S. Citrus limonoids interfere with Vibrio harveyi cell-cell signalling and biofilm formation by modulating the response regulator LuxO. Microbiology 2011, 157, 99-110. [CrossRef] [PubMed]

17. Reynertson, K.A.; Yang, H.; Jiang, B.; Basile, M.J.; Kennelly, E.J. Quantitative analysis of antiradical phenolic constituents from fourteen edible Myrtaceae fruits. Food Chem. 2008, 109, 883-890. [CrossRef]

18. Siani, A.C.; Nakamura, M.J.; D'Avila, L.A.; Lima, A.M.B. Selective and cost effective protocol to separate bioactive triterpene acids from plant matrices using alkalinized ethanol: Application to leaves of Myrtaceae species. Pharmacogn. Mag. 2015, 11, 470-476. [CrossRef] [PubMed]

19. Saber, F.R.; Abdelbary, G.A.; Salama, M.M.; Saleh, D.O.; Fathy, M.M.; Soliman, F.M. UPLC/QTOF/MS profiling of two Psidium species and the in-vivo hepatoprotective activity of their nano-formulated liposomes. Food Res. Int. 2018, 105, 1029-1038. [CrossRef] [PubMed]

20. Mahrous, E.A.; Al-Abd, A.; Salama, M.; Fathy, M.; Soliman, F.; Saber, F.R. Cattleianal and Cattleianone: Two New Meroterpenoids from Psidium cattleianum leaves and their selective antiproliferative action against human carcinoma cells. Molecules 2021, 26, 2891. [CrossRef]

21. Oyedeji, O.O.; Lawal, O.A.; Shode, F.O.; Oyedeji, A. Chemical Composition and Antibacterial Activity of the Essential Oils of Callistemon citrinus and Callistemon viminalis from South Africa. Molecules 2009, 14, 1990-1998. [CrossRef]

22. Siddique, S.; Perveen, Z.; Nawaz, S.; Shahzad, K.; Ali, Z. Chemical Composition and Antimicrobial Activities of Essential Oils of Six Species from Family Myrtaceae. J. Essent. Oil Bear. Plants 2015, 18, 950-956. [CrossRef]

23. Xiang, Y.-Q.; Liu, H.; Zhao, L.-Y.; Xu, Z.-F.; Tan, H.-B.; Qiu, S.-X. Callistemenonone A, a novel dearomatic dibenzofuran-type acylphloroglucinol with antimicrobial activity from Callistemon viminalis. Sci. Rep. 2017, 7, 1-8. [CrossRef] [PubMed] 
24. Shehabeldine, A.M.; Ashour, R.M.; Okba, M.M.; Saber, F.R. Callistemon citrinus bioactive metabolites as new inhibitors of methicillin-resistant Staphylococcus aureus biofilm formation. J. Ethnopharmacol. 2020, 254, 112669. [CrossRef] [PubMed]

25. El-Shiekh, R.; Hassan, M.; Hashem, R.; Abdel-Sattar, E. Bioguided Isolation of Antibiofilm and Antibacterial Pregnane Glycosides from Caralluma quadrangula: Disarming multidrug-resistant pathogens. Antibiotics 2021, 10, 811. [CrossRef]

26. Martínez, O.F.; Cardoso, M.; Ribeiro, S.; Franco, O.L. Recent advances in anti-virulence therapeutic strategies with a focus on dismantling bacterial membrane microdomains, toxin neutralization, quorum-sensing interference and biofilm inhibition. Front. Cell. Infect. Microbiol. 2019, 9, 74. [CrossRef] [PubMed]

27. Hall, S.; McDermott, C.; Anoopkumar-Dukie, S.; McFarland, A.J.; Forbes, A.; Perkins, A.V.; Davey, A.K.; Chess-Williams, R.; Kiefel, M.J.; Arora, D.; et al. Cellular Effects of Pyocyanin, a Secreted Virulence Factor of Pseudomonas aeruginosa. Toxins 2016, 8 , 236. [CrossRef]

28. Hoge, R.; Pelzer, A.; Rosenau, F.; Wilhelm, S.; Duesseldorf, H.-H.-U. Weapons of a pathogen: Proteases and their role in vir-ulence of Pseudomonas aeruginosa. Curr. Res. Technol. Educ. Top. Appl. Microbiol. Microb. Biotechnol. 2010, 2, 383-395.

29. Sarkisian, S.A.; Janssen, M.J.; Matta, H.; Henry, G.E.; Laplante, K.L.; Rowley, D.C. Inhibition of Bacterial Growth and Biofilm Production by Constituents from Hypericum spp. Phytother. Res. 2011, 26, 1012-1016. [CrossRef]

30. Biessy, A.; Filion, M. Phloroglucinol Derivatives in Plant-Beneficial Pseudomonas spp.: Biosynthesis, Regulation, and Functions. Metabolites 2021, 11, 182. [CrossRef]

31. El-Sayed, N.; Samir, R.; Abdel-Hafez, L.J.M.; Ramadan, M. Olive Leaf Extract Modulates Quorum Sensing Genes and Biofilm Formation in Multi-Drug Resistant Pseudomonas aeruginosa. Antibiotics 2020, 9, 526. [CrossRef] [PubMed]

32. Zhou, J.-W.; Luo, H.-Z.; Jiang, H.; Jian, T.-K.; Chen, Z.-Q.; Jia, A.-Q. Hordenine: A Novel Quorum Sensing Inhibitor and Antibiofilm Agent against Pseudomonas aeruginosa. J. Agric. Food Chem. 2018, 66, 1620-1628. [CrossRef] [PubMed]

33. Froes, T.; Nicastro, G.G.; Pereira, T.D.O.; Carneiro, K.D.O.; Reis, I.M.A.; Conceição, R.S.; Branco, A.; Ifa, D.R.; Baldini, R.L.; Castilho, M.S. Calycopterin, a major flavonoid from Marcetia latifolia, modulates virulence-related traits in Pseudomonas aeruginosa. Microb. Pathog. 2020, 144, 104142. [CrossRef] [PubMed]

34. Tan, H.; Liu, H.; Zhao, L.; Yuan, Y.; Li, B.; Jiang, Y.; Gong, L.; Qiu, S. Structure-activity relationships and optimization of acyclic acylphloroglucinol analogues as novel antimicrobial agents. Eur. J. Med. Chem. 2017, 125, 492-499. [CrossRef]

35. Ardizzoni, A.; Hansen, H.; Dombernowsky, P.; Gamucci, T.; Kaplan, S.; Postmus, P.; Giaccone, G.; Schaefer, B.; Wanders, J.; Verweij, J. Topotecan, a new active drug in the second-line treatment of small-cell lung cancer: A phase II study in patients with refractory and sensitive disease. The European Organization for Research and Treatment of Cancer Early Clinical Studies Group and New Drug Development Office, and the Lung Cancer Cooperative Group. J. Clin. Oncol. 1997, 15, 2090-2096. [CrossRef] [PubMed]

36. Abbas, H.A.; Shaldam, M.; Eldamasi, D. Curtailing Quorum Sensing in Pseudomonas aeruginosa by Sitagliptin. Curr. Microbiol. 2020, 77, 1051-1060. [CrossRef]

37. Jander, G.; Rahme, L.G.; Ausubel, F.M. Positive Correlation between Virulence of Pseudomonas aeruginosa Mutants in Mice and Insects. J. Bacteriol. 2000, 182, 3843-3845. [CrossRef] [PubMed]

38. Khalil, M.A.; Hager, R.; Reheem, F.A.-E.; Mahmoud, E.E.; Samir, T.; Moawad, S.S.; Hefzy, E.M. A Study of the Virulence Traits of Carbapenem-Resistant Klebsiella pneumoniae Isolates in a Galleria mellonella Model. Microb. Drug Resist. 2019, 25, $1063-1071$. [CrossRef] [PubMed]

39. Khalil, M.A.F.; Moawad, S.S.; Hefzy, E.M. In vivo activity of co-trimoxazole combined with colistin against Acinetobacter baumannii producing OXA-23 in a Galleria mellonella model. J. Med. Microbiol. 2019, 68, 52-59. [CrossRef] [PubMed]

40. Desbois, A.P.; Coote, P.J. Chapter 2-Utility of Greater Wax Moth Larva (Galleria mellonella) for Evaluating the Toxicity and Efficacy of New Antimicrobial Agents. In Advances in Applied Microbiology; Laskin, A.I., Sariaslani, S., Gadd, G.M., Eds.; Academic Press: Cambridge, MA, USA, 2012; pp. 25-53.

41. Allegra, E.; Titball, R.W.; Carter, J.; Champion, O.L. Galleria mellonella larvae allow the discrimination of toxic and non-toxic chemicals. Chemosphere 2018, 198, 469-472. [CrossRef]

42. Tharmalingam, N.; Khader, R.; Fuchs, B.B.; Mylonakis, E. The Anti-virulence Efficacy of 4-(1,3-Dimethyl-2,3-Dihydro-1HBenzimidazol-2-yl)Phenol Against Methicillin-Resistant Staphylococcus aureus. Front. Microbiol. 2019, 10, 1557. [CrossRef]

43. Bloor, S.J. Antiviral Phloroglucinols from New Zealand Kunzea Species. J. Nat. Prod. 1992, 55, 43-47. [CrossRef]

44. Salem, M.A.; El-Shiekh, R.A.; Hashem, R.A.; Hassan, M. In vivo Antibacterial Activity of Star Anise (Illicium verum Hook.) Extract Using Murine MRSA skin infection model in relation to its metabolite profile. Infect. Drug Resist. 2021, 14, 33-48. [CrossRef]

45. Sultan, A.M.; Nabiel, Y. Tube method and Congo red agar versus tissue culture plate method for detection of biofilm production by uropathogens isolated from midstream urine: Which one could be better? Afr. J. Clin. Exp. Microbiol. 2018, 20, 60. [CrossRef]

46. Nithya, C.; Devi, M.G.; Pandian, S.K. A novel compound from the marine bacteriumBacillus pumilusS6-15 inhibits biofilm formation in Gram-positive and Gram-negative species. Biofouling 2011, 27, 519-528. [CrossRef] [PubMed]

47. Karatuna, O.; Yagci, A. Analysis of quorum sensing-dependent virulence factor production and its relationship with antimicrobial susceptibility in Pseudomonas aeruginosa respiratory isolates. Clin. Microbiol. Infect. 2010, 16, 1770-1775. [CrossRef]

48. Vijayaraghavan, P.; Vincent, S.G.P. A simple method for the detection of protease activity on agar plate using bromocresolgreen dye. J. Biochem. Technol. 2013, 4, 628-630. 
49. Peleg, A.Y.; Jara, S.; Monga, D.; Eliopoulos, G.M.; Moellering, R.C.; Mylonakis, E. Galleria mellonella as a Model System To Study Acinetobacter baumannii Pathogenesis and Therapeutics. Antimicrob. Agents Chemother. 2009, 53, 2605-2609. [CrossRef] [PubMed]

50. CLSI. Performance Standards for Antimicrobial Susceptibility Testing, 26th ed.; CLSI Supplement M100S; Clinical and Laboratory Standards Institute: Wayne, PA, USA, 2016. 